\title{
ROBOTIC PROCESS AUTOMATION IN SOFTWARE PERFORMANCE TESTING WORKLOAD MODELING
}

\author{
Tirthankar Sengupta \\ Senior Consultant Performance Engineer (BE, MBA, ISTQB Certified) \\ International Business Machines Corporation (IBM), Kolkata, West Bengal, India
}

\begin{abstract}
Software Performance Testing(SPT) is the kind of Non-Functional Testing(NFT) to prove the to be delivered system by the project team/product team is working as expected with respect to system health, consistency, endurance robustness etc.

This testing is a very critical part of system going live. Now a days customers/stakeholders are very keen to carry on this test to get absolute confidence to the software product they are going to use for their business. It has been seen several instances in the history of software industry ,live application has been demoted or scrapped due to the system not able to behave as it is expected with its features and functionalities when the system is used concurrently in high load.This type of verification can be only simulated when we do performance testing.

Now workload distribution for performance testing till date has been generally performed by manually capturing load details like list of very frequently performed critical transactions, no. of call/hours, no. of concurrent users running from the log or details from business. And it's a laborious time consuming job.

With the advent of Robotic Process Automation (RPA) we can overcome the drawbacks of manual hurdles workload model with a futuristic reusable and reliable one, about which I discussed in following sections.
\end{abstract}

Keywords: Performance Test, Workload, Endurance, (Robotic process Automation) RPA, Software Non Functional Test, NFT etc.

Cite this Article: Tirthankar Sengupta, Robotic Process Automation in Software Performance Testing Workload Modeling, International Journal of Computer Engineering and Technology, 10(2), 2019, pp. 25-30.

http://iaeme.com/Home/issue/IJCET?Volume=10\&Issue=2

\section{INTRODUCTION}

During last 20 years research and industry has found and realized the importance to commensurate non function requirements in Software Requirement Specification (SRS) document as need of customer apart from business functionality and/or usability feature specifications. 
Out of these performance is one of the most important indicator in order to meet nonfunctional requirements.

In software quality assurance, performance testing is in general, a testing practice performed to determine how a system performs in terms of responsiveness and stability under a particular workload. It can also serve to investigate, measure, validate or verify other quality attributes of the system, such as scalability, reliability and resource usage.[1]

There were in general two ways the NFRs provided. One is from client's own expectation and another one is that try a load till it breaks or third based on similar past experience or adhoc basis to put load.

If the performance workload planning not properly done it will affect proper system behavior and capability check and can cause severe issue in application in production and may cause the application itself to be suspended and financial and crediting losses.

Robotic Process automation has strong potential of mitigating these risks above and improve the workload modeling to be more accurate.

\section{TRADITIONAL PERFORMANCE WORKLOAD DISTRIBUTION}

When we traditionally do software requirement analysis for predicted load when the application will be live we generally follow various mechanism like talking to the stake holder/client about the user base of the to be system, what are the critical business transactions, what should be the expected response time for critical business functions of the application, no. of concurrent activity etc. Often we do not get concrete answer to all the questions and vary from one person to another and as well most of the cases the customer answers based on his/her view point also of course this method is time consuming, prone to human error and varies between industries/business domain.

There are also cases where a single business person does not have the sufficient information about the nonfunctional specifications of the software in terms of performance metrices like expected response time, expected system load in production etc. So the existing system logs has to be analyzed to get those information's like how many users logged in an hour, which are the top methods which were called very frequently etc. to predict the load of the new systems form existing systems. In these cases workload modeling [2] highly depend on assumption, word of mouth and intuition .And to compile these unstructured information from different sources is a time consuming activity.

\section{ROBOTIC PROCESS AUTOMATION (RPA) BASED LOAD MODELING}

To overcome the time consuming traditional performance test model and increase its accuracy we can use RPA.

Robotic process automation (or RPA) is a form of business process automation technology based on the notion of software robots or artificial intelligence (AI) workers.[3]

As for example if we are planning make workload model for a new retail industry feature application for a retail website we can follow the below steps using RPA tools. It can be applied for application across every industry.

- Screen scrapping of the log files, deployed analytics tool to extract which are the most frequent activities performed in a banking website, how many users logged in in a day, what is the peak load etc. 
Robotic Process Automation in Software Performance Testing Workload Modeling

- Also using google surveys/ we can send questionnaire to client and capture the responses like what is the busiest time (peak time), peak no. of user, which transactions are used most, what is the acceptable limit of search transactions or update transactions etc.

Below is some examples of capturing workload planning information using a RPA software (UI Path) from awstat log analytics tool.

Extract Wizard

Preview Data

\begin{tabular}{|c|c|c|c|c|c|}
\hline 115 different $p$ & Viewed & Average size & Entry & Exit & Column-5 \\
\hline /rss-fr & 65 & $5.81 \mathrm{~KB}$ & 59 & 60 & \\
\hline /mes-activites- & 833 & $4.12 \mathrm{~KB}$ & 458 & 532 & \\
\hline l & 6,017 & $5.23 \mathrm{~KB}$ & 5,428 & 5,288 & \\
\hline /mes-sites-wet & 67 & $4.41 \mathrm{~KB}$ & & 5 & \\
\hline /spip.php & 841 & $1.57 \mathrm{~KB}$ & 283 & 324 & \\
\hline Others & 887 & $6.88 \mathrm{~KB}$ & 314 & 314 & \\
\hline /mes-activites- & 62 & $13.28 \mathrm{~KB}$ & 23 & 23 & \\
\hline /mes-activites- & 371 & $5.17 \mathrm{~KB}$ & 108 & 155 & \\
\hline /mes-activites- & 376 & $6.44 \mathrm{~KB}$ & 194 & 140 & \\
\hline /rss-en & 522 & $10.28 \mathrm{~KB}$ & 121 & 122 & \\
\hline /mes-activites- & 307 & $4.95 \mathrm{~KB}$ & 90 & 115 & \\
\hline
\end{tabular}

Edit Data Definition Maximum number of results ( 0 for all)

100 
Ui Extract Wizard

Preview Data

\begin{tabular}{|l|l|l|l|l|l|}
\hline Column-0 & Column-1 & Column-2 & Column-3 & Column-4 & Column-5 \\
\hline Month & Unique visitors & Number of visi & Pages & Hits & Bandwidth \\
\hline Jan 2018 & 6,687 & 8,200 & 23,928 & 38,961 & $716.45 \mathrm{MB}$ \\
\hline Feb 2018 & 3,815 & 6,283 & 11,188 & 19,504 & $317.85 \mathrm{MB}$ \\
\hline Mar 2018 & 2,597 & 7,078 & 10,348 & 15,363 & $121.12 \mathrm{MB}$ \\
\hline Apr 2018 & 2,304 & 5,921 & 8,437 & 12,886 & $120.89 \mathrm{MB}$ \\
\hline May 2018 & 410 & 538 & 680 & 1,130 & $7.83 \mathrm{MB}$ \\
\hline Jun 2018 & 0 & 0 & 0 & 0 & 0 \\
\hline Jul 2018 & 0 & 0 & 0 & 0 & 0 \\
\hline Aug 2018 & 0 & 0 & 0 & 0 & 0 \\
\hline Sep 2018 & 0 & 0 & 0 & 0 & 0 \\
\hline Oct 2018 & 0 & 0 & 0 & 0 & 0 \\
\hline Nov 2018 & 0 & 0 & 0 & 0 & 0 \\
\hline Dec 2018 & 0 & 0 & 0 & 0 & $1.25 \mathrm{~GB}$ \\
\hline Total & 15,813 & 28,020 & 54,581 & 87,844 & \\
\hline & & & & & \\
& & & & & \\
\end{tabular}

Edit Data Definition Maximum number of results ( 0 for all) 100

Sample Questionnaire forms to be sent to stakeholders for gathering nonfunctional workload information 


\title{
NFR Requirement Analysis
}

\author{
* Required \\ Industry Type \\ Financial \\ Retails \\ Utilities \\ Other:
}

Maximum No. Of User *

Your answer

What is the Peak Time duration

Your answer

\section{Top frequently used Business Critical Transactions *}

\section{Your answer}

Once we get these information we can very easily construct documented structures workload profile with contains following information to use them for actual performance testing planning and execution.

As

- Top business critical and frequently executed transaction

- Daily/Month avg no. no. of Transactions

- No. of maximum user using the system during peak

- Peak Time duration

- Expected Response of view/update operations etc. 
In this way when all the profiling information is captured we can also store the details in tabular format and use it.

\section{CONCLUSIONS}

In this paper I reviewed performance test workload modeling using automation to overcome manual redundant activities and make the process more fine-tuned and easier to use.

I explained the application of Robotic process automation for the gathering and designing of performance engineering workload model and explained the drawbacks of manual modeling generation process also explained the sample way of using the robotic automation tool to capture statistics as well as using automated survey form to capture NFR requirement from user where log information is not available.

Development and Implementation of new automated process will make the performance test workload modeling more accurate and easy to create.

It is a first step in implementing robotic automation in performance testing modeling.

A future work focus is on incorporating of automating performance test cases integrating performance testing tool with robotic process automation.

\section{REFERENCES}

[1] Dhiman, S., \& Shara, P. (2018). Performance Testing: A Comparative Study and Analysis of Web Service Testing Tools. International Journal of Recent Trends in Engineering and Research, 4(3), 95-100. doi:10.23883/ijrter.2018.4102.tbuwk

[2] http://www.agileload.com/agileload/blog/2013/06/12/performance-test-workloadmodeling

[3] Borland, J., \& Coelli, M. (2017). Are Robots Taking Our Jobs? Australian Economic Review, 50(4), 377-397. doi:10.1111/1467-8462.12245 